\title{
Research on seepage characteristics of Hongshiyan landslide dam
}

\author{
Jun Yan ${ }^{\text {a }}$, Ziwen Wang ${ }^{b}$, Yingqi Weic, and Hong Cai ${ }^{\mathrm{d}}$
}

China Institute of Water Recources and Hydropower Research, State Key Laboratory of Simulation and Regulation of Water Cycle in River Basin, Beijing 100048.China

ayanjunwuhan@163.com, bwzwqiaonan@163.com, cweiyq@iwhr.com, dcaihong@iwhr.com

Keywords: Hongshiyan, landslide dam, permanent management, finite element method, seepage characteristics.

\begin{abstract}
The Hongshiyan landslide dam is composed of landslide body accumulated in river. Its composition, which includes series of questions such as unevenness, loosening and gradation uncertainty, is complex and random. In order to ensure the safety of the dam body, the joint seepage control measures of impervious wall and the impervious blanket are designed. In this paper, to determine the rationality of the renovation measures, the 3D finite element modeling on landslide dam area is used to calculate the seepage characteristics of the landslide dam body and the ground under the normal water level. Meanwhile, through the quantitative analysis of the factors such as the contour of the water head, the seepage discharge and the hydraulic slope, it is proved the rationality of the seepage control measures and provides experience for the same type of engineering.
\end{abstract}

\section{Introduction}

Hongshiyan landslide dam is located in the Niulan River between Ludian and Qiaojia, Yunnan Province. It is caused by the earthquake landslides on both sides of the mountain [1]. The dam body is located at $1200 \mathrm{~m}$ downstream of the dam in the original Hongshiyan hydropower station. The right bank landslide slides towards the river bed to form the debris flow that move to downstream in 2014. This movement exacerbates the deformation and damage of the middle and upper slope rock mass, which causes landslide of the rock mass and accumulates to form landslide dam. As shown in Fig.1, the collapse of the right bank along the river direction of the length of the mountain is about $890 \mathrm{~m}$, the height of trailing edge of the rock is about $600 \mathrm{~m}$, and the maximum slope elevation is about $1843.7 \mathrm{~m}$.

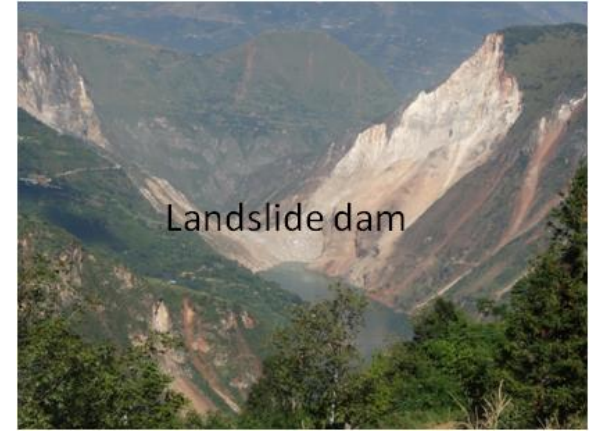

Fig.1 Recent situation of the Hongshiyan landslide dam.

\section{Hydrogeological conditions}

(1)The base of the river bed which is covered with 25 40m thickness alluvial desposits is sand and gravel sand layer by the right bank high-speed collapse alluvial compaction. Due to low permeability of the layer, its bearing capacity can meet the requirements. Under the pressure of the high water head, there may be infiltration problems. Because the upper and lower part of the dam is covered with low pressure, there are problems about shock impact on sand liquefaction. However, the slope of upstream and downstream is very slow, the local sand liquefaction does not affect the stability of the whole dam body. 
(2)The riverbed dam foundation and the right bank dam foundation below alluvial layer are Ordovician shale, shaly sandstone, quartz sandstone and dolomite, which is composed of thin layer structure and flat layer. The joint is developed relatively, and the dam area karst is not developed, mostly strong weathering to weak weathering. The bearing capacity of rock mss is enough to meet the requirements of dam foundation. Additionally, It is necessary to consider anti-seepage measures because of the developments of Bedrock bedding and fissure caused seepage problems.

(3)The width of the left bank bottom of ancient landslide is about $1200 \mathrm{~m}$. The projected length of the top of the stack is about $900 \mathrm{~m}$. The average thickness is about $70 \mathrm{~m}$. The landslide volume is about $5670 \times 10^{4} \mathrm{~m}^{3}$. The above height of the dam body is about $310 \mathrm{~m}$. The accumulation is so dense that it is no aerial view. The slope is $36^{\circ}$ when the elevation is below $1400 \mathrm{~m}$, oppositely, the slope is only $18^{\circ}$. Hongshiyan landslide dam mainly compose of gravel, stone clip silt clay and clay. The size of the largest stone is about $15 \mathrm{~m}$.

(4)After the collapse of the earthquake on the right bank, the terrain has undergone great changes. The upper part of the trailing edge became the cliff that the maximum height is about $350 \mathrm{~m}$. The central formation of a cross river inclines towards the near horizontal and the downstream, and below this slope is a cliff.

\section{Permanent remediation measures}

The seepage control wall and impervious curtain are adopted for seepage control of the dam body, and seepage grouting is carried out through grouting hole on both sides of the dam. As the check water level is $1205.70 \mathrm{~m}$, the elevation of the anti-seepage wall on both sides is $1206.00 \mathrm{~m}$, and the elevation of the emergency spillway is $1200.00 \mathrm{~m}$. In order to facilitate the construction of the porous wall, the excavated section of the weir was excavated by the anti-seepage line, bottom elevation $1200.00 \mathrm{~m}$, bottom width $15 \mathrm{~m}$, side slope $1: 1.5$. Combined with the water head of barrier body and material composition, the vertical anti-seepage scheme of the curtain grouting for the lower end of the plastic concrete barrier is proposed [2]. The thickness of the impervious wall is about $406.00 \mathrm{~m}$, the thickness is $1.2 \mathrm{~m}$ and the deepest position is about $125 \mathrm{~m}$. In order to reduce the influence of inhomogeneous settlement of the barrier body on the cut-off wall and the leakage and collapse of the cut-off wall during the construction process, At the same time, according to the design principle of the core wall rockfill dam, one row of rockfill curtain grouting are installed on the downstream wall of the impervious wall, grouting reinforcement of the dam body (shown in Fig. 2).

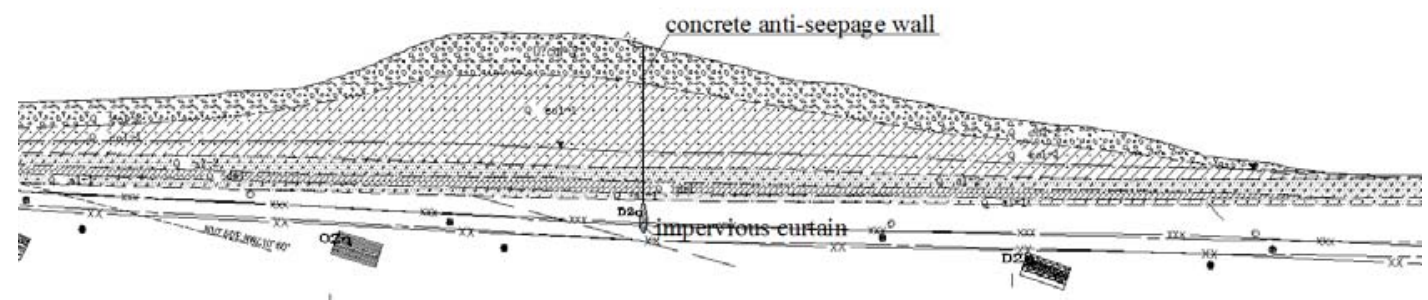

Fig.2 The seepage control section of Hongshiyan landslide dam

\section{Study on the characteristics of seepage}

\subsection{Seepage analysis theory}

The seepage control equation of the three-dimensional stable Darcy seepage field [3-8] is:

$$
-\frac{\partial}{\partial x_{i}}\left(k_{i j} \frac{\partial h}{\partial x_{j}}\right)+Q=0
$$

In the formula: $x_{i}$ is the coordinate, $i=1,2,3 ; k_{i j}$ is the second order symmetrical darcy permeability tensor. It describes the permeability anisotropy of rock mass. $h=x_{3}+p / \gamma$ is the total head, $x_{3}$ is the elevation head, $p / \gamma$ is the pressure head; $Q$ is the source or sink of the seepage field. 
The theory of boundary conditions is as follows:

$$
\begin{gathered}
\left.h\right|_{\Gamma_{1}}=h_{1} \\
-\left.k_{i j} \frac{\partial h}{\partial x_{j}} n_{i}\right|_{\Gamma_{3}}=q_{n} \\
-\left.k_{i j} \frac{\partial h}{\partial x_{j}} n_{i}\right|_{\Gamma_{3}}=0 \text { and } h=x_{3} \\
-\left.k_{i j} \frac{\partial h}{\partial x_{j}} n_{i}\right|_{\Gamma_{4}} \geq 0 \text { and } h=x_{3}
\end{gathered}
$$

In the formula: $h_{1}, h_{2}$ are the functions. $n_{i}$ is the outside normal cosine of seepage boundary surface. $\Gamma_{1}$ is the first type of seepage boundary condition of the known head; $\Gamma_{2}$ is the second type of seepage boundary condition of the known seepage flow. $\Gamma_{3}$ is the seepage free surface between the seepage current and the imaginary area in the seepage field, and it does not know its exact position in advance and exhibits the boundary nonlinearity. $\Gamma_{4}$ is the seepage surface, because it does not know the specific location of the seepage escape point $E$ in advance and the specific size of the whole escape surface, this is a boundary nonlinear seepage problem which needs a value of iteration. $q_{n}$ is the boundary normal flow and the outflow is positive.

\subsection{Finite element analysis model}

The calculation range of the seepage field calculation model is: 1) the left bank: from the river bed center line to the left bank of the mountain to about $700.0 \mathrm{~m}$; 2) the right bank: from the river bed center line to the mountain to take about $700.0 \mathrm{~m}$; 3) upstream: upstream of the anti-seepage wall axis to $850.0 \mathrm{~m}$ away; 4) downstream: take the downstream of the wall of $700.0 \mathrm{~m}$ away; Elevation: Take the $800.0 \mathrm{~m}$ elevation.

In this study, the main body structure and seepage control measures of the weir body are simulated by the finer simulation of the three-dimensional seepage finite element analysis of the Hongshiyanyan Lake, which includes the structure of the dam body (landslide, alluvial Layer, etc.), concrete plastic cut-off wall, grouting curtain, etc ., the main foundation of the dam foundation, bedrock simulation, including the cover, strong weathered bedrock, weak weathered bedrock and micro-weathering bedrock and so on.

The model is composed of hexahedron 8 node isoparametric elements and local facies pentahedron 6 junction transitional isoparametric elements, which is mainly composed of 93634 units and 100812 nodes. Fig. 3 is a three-dimensional finite element mesh model after generation, and Fig.4 is a typical cross-sectional view of the dam body in the grid.

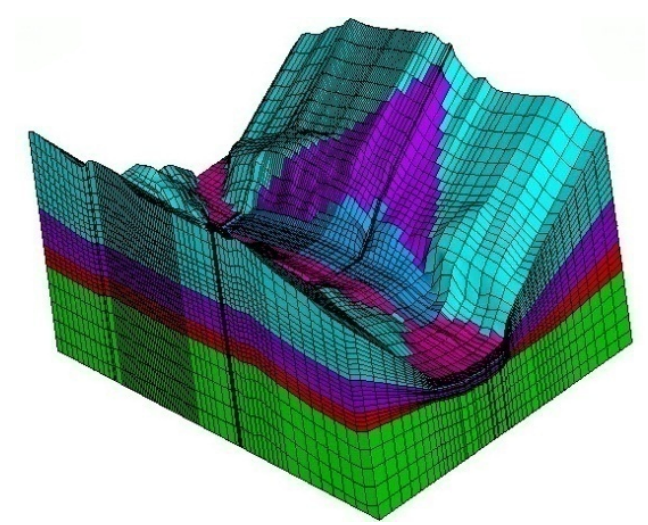

Fig.3 The 3D seepage field model of Hongshiyan landslide dam 


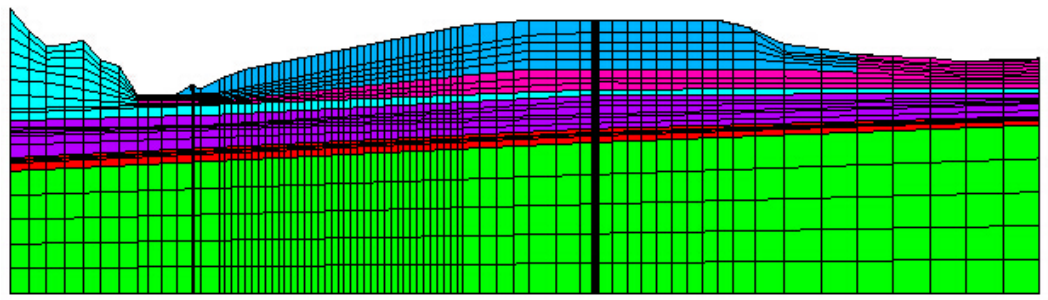

Fig.4 The grid arrangement of Hongshiyan landslide dam

The permeability coefficients of various materials adopted in the calculation are referred to the hydrogeological data and laboratory test results. It is compared with those of the same type of projects. The specific values are shown in table 1:

Table 1. The calculation values on 3D seepage finite element

\begin{tabular}{ccc}
\hline Material & \multicolumn{2}{c}{ Hydraulic conductivity $(\mathrm{cm} / \mathrm{s})$} \\
\cline { 2 - 3 } $\mathrm{k}_{\mathrm{y}}$ & $1.0 \times 10^{-4}$ \\
Strong weathering bedrock & $1.0 \times 10^{-4}$ & $5.0 \times 10^{-5}$ \\
Weak weathering bedrock & $5.0 \times 10^{-5}$ & $1.0 \times 10^{-5}$ \\
Slight weathering bedrock & $1.0 \times 10^{-5}$ & $5.0 \times 10^{-3}$ \\
Collapse deposits & $5.0 \times 10^{-3}$ & $1.0 \times 10^{-3}$ \\
Q $^{\text {del }}$ channel overburden & $1.0 \times 10^{-3}$ & $1.0 \times 10^{-7}$ \\
Plastic concrete anti-seepage wall & $1.0 \times 10^{-7}$ & $1.0 \times 10^{-5}$ \\
\hline
\end{tabular}

\subsection{Analysis of seepage characteristics}

In order to effectively control the seepage through the weir body, a plastic concrete cut-off wall and an anti-seepage curtain are arranged in the barrier body. In this paper, the seepage characteristics of the weir body during the normal water level are calculated and analyzed. The main results are shown in Fig. 5 to Fig. 9:

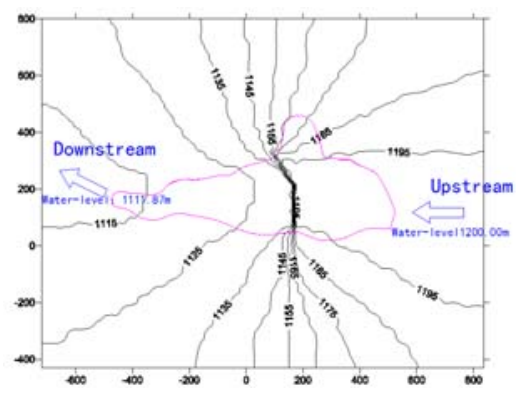

Fig. 5 The water head contour distribution of downstream reservoir area

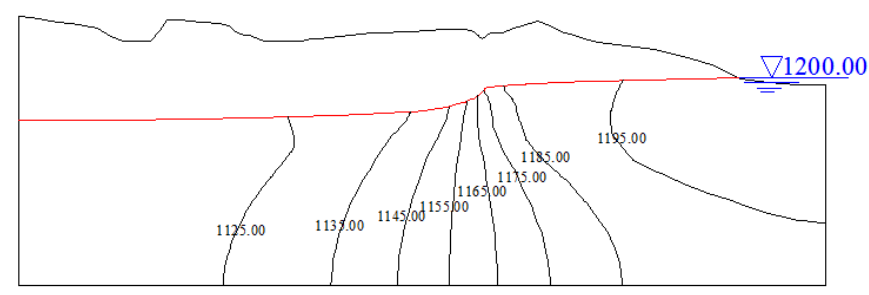

Fig. 6 The water head contour distribution of the right bank

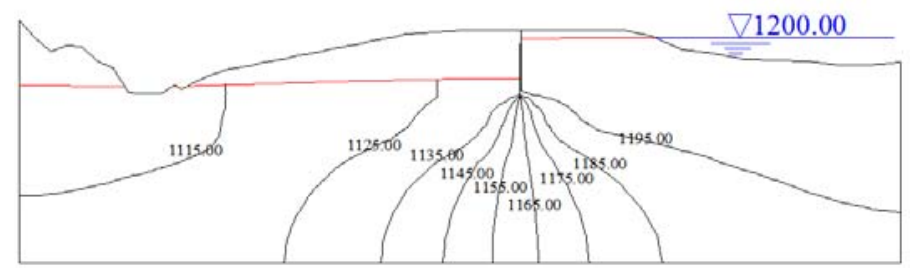

Fig. 7 The water head contour distribution of downstream $0+90.0$ 


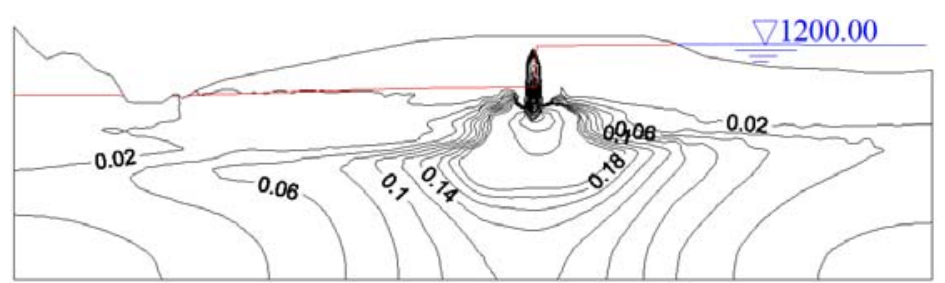

Fig. 8 Hydraulic gradient contour line of downstream 0+90.0

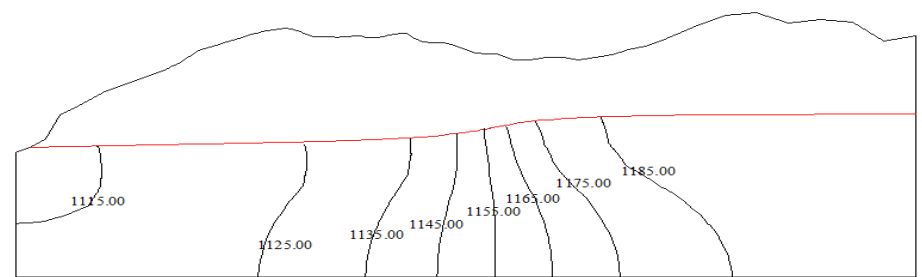

Fig. 9 The water head contour distribution of the left bank

(1)The seepage field and other head line distribution

The results show that the seepage characteristics of the dam body in the normal water level have typical three-dimensional seepage characteristics. After the impoundment, the reservoir water not only passes through the dam foundation permeable belt to the downstream river bed Leakage, but also through the cross-strait permeable belt around the left and right abutment to the river bed and downstream leakage(alluvial material $\left(\mathrm{Q}^{\mathrm{pl}+\mathrm{al}}\right)$ landslide accumulation $\left(\mathrm{Q}^{\mathrm{del}}\right)$, embankment deposits $\left(\mathrm{Q}^{\mathrm{col}+\mathrm{dl}}\right)$, strong weathering bedrock and weak weathering bedrock, etc.) have a certain permeability, the comparison of working conditions 1 , after the impoundment of the seepage body leakage, the basis of leakage and dam leakage, the design of concrete cut-off wall, curtain grouting seepage is appropriate.

(2) Analysis of the effect of seepage control measures

The following is mainly for the seepage control measures and seepage safety analysis under the normal water level, including the barrier rock in the plastic concrete cut-off wall, the foundation curtain grouting, the left and the right curtain curtain grouting and other parts.

The plastic concrete cut-off wall: under the normal water level of $1200.00 \mathrm{~m}$, the barrier rock in the plastic concrete cut-off wall upstream head is about $1197.00 \mathrm{~m} \sim 1199.0 \mathrm{~m}$, and the downstream wall of the wall is about $1125.00 \sim 1126.5 \mathrm{~m}$. The maximum cuthead of the plastic concrete wall is $74.00 \mathrm{~m}$, accounting for $84 \%$ of the upstream and downstream head difference $(1200.00-1111.87=88.13 \mathrm{~m})$, and the concrete cut-off wall has played a good role in anti-seepage. The thickness of the cutoff wall is $1.20 \mathrm{~m}$, and the maximum penetration is 50.6 at the maximum cross section which indicating that the impervious wall(less than 1/50000 times that of the dam body and is 1/10000 times larger than that of the river bed cover) have a greater anti-seepage effect.

The anti-seepage curtain: the basic anti-seepage curtain is based on the maximum cross-section to withstand the maximum seepage slope of 18.23 . The permeability of the anti-seepage curtain is $1 / 10$ $\sim 1 / 50$ times smaller than the basic rock mass, and can also play a certain anti-seepage effect. The water level at the end of the slope on the two sides is low. It is said that the anti-seepage curtain of the dam which is designed by the project is effective.

(3) Seepage calculation

The seepage flow in the weir body and the foundation is one of the main contents of the seepage control design. based on the analysis of the finite element calculation in normal operation condition of the whole three dimensional seepage flow characteristics, and specifically for the dam body under the normal operation of the project: through the seepage flow calculation and analysis under the normal storage level, the total seepage flow calculation value by the dam body is $13255.1 \mathrm{~m}^{3} / \mathrm{d}$, which is about $1 / 4$ of no seepage control measures of infiltration flow. Among them, by the dam body leakage quantity is $9233.1 \mathrm{~m}^{3} / \mathrm{d}$, which is about $70 \%$ of total amount, the amount of leakage through this bedrock is $4022.0 \mathrm{~m}^{3} / \mathrm{d}$. The seepage flow of the left bank is $2038.2 \mathrm{~m}^{3} / \mathrm{d}$, and the right bank is $2087.1 \mathrm{~m}^{3} / \mathrm{d}$. 
(4) Calculation of hydraulic ratio

Concrete cut-off wall: due to the dam body rock filled with concrete cut-off wall, a lot of the water head is reduced. The dam body concrete concrete cut-off wall at the hydraulic ratio is larger, the maximum reached 50.6, which also shows the impervious wall plays a good role in anti-seepage.

Dam body: Due to the anti-seepage of the seepage prevention wall, the groundwater level of the barrier part is lower in the following parts of the cutoff wall, and most of the dam body is in a dry state. Therefore, the overall hydraulic ratio of the dam body decreases. The hydraulic ratio in the rockfill is 0.04 , and the ratio of the contact with the bedrock is 0.08 .

Downstream flow stability: the results show that the escaped elevation of the downstream flow after the reservoir is low, which is about $1112.4 \mathrm{~m}$ that less than $1.0 \mathrm{~m}$ higher than the downstream water level of $1111.87 \mathrm{~m}$. Therefore, the escaped gradient of dam body on the downstream surface is only 0.02 .

\section{Conclusion}

Because of the rock and the foundation bed has the high permeability, the stratification of the basic rock mass is significant, and the strong weathering layer and the weak weathering layer are shallow, after the reservoir is impounded, the rock and rock foundation will become the main leakage channel, which is the main problem of anti-seepage measures to be solved. The results of three-dimensional seepage calculation under normal water storage show that the seepage control system with concrete cut-off wall + curtain grouting can meet the seepage requirements of the barrier body, which can provide a good reference for the seepage control of similar projects.

\section{Acknowledgements}

The financial support to this study by National youth natural science foundation (51409278); National key basic research and development plan (project 973) (2014CB047004); IWHR Research\& Development Support Program (GE0145B512016) are deeply appreciated.

\section{References}

[1]. A brief consultation report on field investigation, test results analysis and management plan of Hongshiyan Landslide Lake at Niulanjiang River in Yunnan province [R]. Kunming investigation and design institute co. LTD, 2015.04, p.40-62.

[2]. The test data of the engineering characteristics for the permanent remediation engineering of Hongshiyan Landslide Lake at Niulanjiang River in Yunnan province [R]. Kunming investigation and design institute co. LTD, 2015.03, p.25-40.

[3]. Zhang Yan. The seepage control technical analysis of plain reservoir [J]. Water Conservancy Science and Technology, Vol.15 (2009) No.1, p.64-66.

[4]. Zheng Hongsheng, Shao Lin, Chen Yuchao. Vertically laying out leakage-proof membrane technology in the application of the levee anti-seepage reinforcement engineering [J]. Water Conservancy and Electric Power Machinery, Vol.28 (2006) No.28, p.430-435.

[5]. Su Bayou, Zhu Yueming. Procedure of nodal virtual flux of seepage free surface for the unchanged grids [J]. Journal of Hohai University, Vol.40 (1991) No.5, p.113-117.

[6]. Luo Sheng, Kang xiaobing. Groundwater environment impact assessment of water conservancy project [J]. Hydroelectric Engineering, Vol.41 (2015) No.3, p.1-3, 10.

[7]. Wang Jinzhi, Chen Wanji, Qi Shuhua. Mixed fixed-point FE method for seepage problems with free surfaces [J]. Journal of Dalian University of Technology, Vol.47 (2008) No.6, p.793-797.

[8]. Pan Shulai, Wang Quanfeng, Yu Jin. Improvement of analysis of free surface seepage problem by using initial flow method [J]. Chinese Journal of Geotechnical Engineering, Vol.34 (2012) No.2,p. 202-209. 